\title{
Nadenke oor die kerkbegrip: Enkele perspektiewe op grond van die Deuteronomistiese geskiedenis
}

A P B Breytenbach

Universiteit van Pretoria

\begin{abstract}
Reflecting on the concept church: Some perspectives from Deuteronomistic history

This article seeks to explain why and how the Old Testament and Deuteronomistic history in particular are essential in our theological reflection on the concept of church. The main trends in the theology of the Deuteronomistic history are discussed, namely that YHWH is a unique, sovereign and almighty God who elected Israel and made a covenant with them. His steadfast love and preparedness to forgive, as well as his judgement on those who disobey him, serve as an appeal to Israel to honor and obey him in absolute loyalty. The article concludes with the notion that the very existence of the religious community is totally dependant on the grace and love of God, and that its members are therefore committed to him and to one another with the prophetic word as their hope for the future.
\end{abstract}

\section{VERANTWOORDING}

\subsection{Algemene opmerkings}

Binne die Nederduitsch Hervormde Kerk van Afrika word daar tans in die teologiese debat onder andere aandag gegee aan die kerkbegrip. Hierdie tema is lank reeds onder bespreking by die Tussenkerklike Kommissie (TKK) waar die Nederduitsch Hervormde Kerk 'n ander standpunt daarop nahou as sy twee gespreksgenote (die Gereformeerde Kerke in Suid-Afrika en die Nederduitse Gereformeerde Kerk) oor veral die aspek van kerkeenheid. In die Nederduitsch Hervormde Kerk van Afrika is die herskryf van die kerkwet en die debat wat daaroor aan die gang is, waarskynlik die grootste stimulus vir die aandag wat 'n saak soos kerkbegrip op die oomblik geniet.

Alhoewel die begrip 'kerk' eintlik in die kader van die Nuwe-Testamentiese en veral tot die periode na die Nuwe-Testamentiese tyd tuishoort, is dit my oortuiging dat daar in ' $n$ teologiese debat oor kerkbegrip ook aan die Ou Testament aandag gegee 
moet word. Die belang van die Ou Testament in hierdie saak het aan die een kant sy grond daarin dat hierdie versameling boeke getuienis is van die bestaan van 'n geloofsgemeenskap (of geloofsgemeenskappe) wat oor eeue eenheid gevind het in die verbondenheid aan die een lewende God. Aan die ander kant staan die geloofsgemeenskap waarvan ons vandag deel is, in 'n tradisie wat die Ou Testament voluit as woord van God, dit wil sê as normatief vir die geloofsgemeenskap in die huidige tyd, aanvaar.

Teologiese nadenke vanuit die Ou Testament oor die kerkbegrip moet egter nie gedoen word vanuit 'n sogenaamde Bybelse teologie waarin daar 'n sentrale tema soos 'koninkryk van God', in aansluiting by Nuwe-Testamentiese inhoud, gekies word en dié 'sentrale tema' dan teruggelees en teruggevind word in die Ou Testament nie. Dit moet byvoorbeeld ook nie gedoen word vanuit 'n begrip-georiënteerde studie wat die inhoud en ontwikkeling van terme en begrippe en daarmee saam die verbande al dan nie tussen Ou en Nuwe Testament navors nie (so Stendebach 1984:211-224). Dit moet

* gedoen word binne die breë kontoere wat die kritiese navorsingsresultate aangedui het;

* gerig wees op die breë teologiese inhoud van 'n bepaalde boek of korpus uit die Ou Testament; en

* die historiese bedding van hierdie teologiese inhoud deeglik in ag neem.

\subsection{Die Deuteronomistiese geskiedenis as korpus - enkele keuses}

Die hipotese van Noth dat die boeke Deuternomium, Josua, Rigters, 1 en 2 Samuel en 1 en 2 Konings die resultaat is van die werk van 'n outeur wat met oorgelewerde materiaal 'n geskiedenis vertel wat strek vanaf die tyd van Moses tot die Babiloniese ballingskap, is welbekend en hoef nie bespreek te word nie (Noth 1943:45-152). Die reaksie wat gevolg het op Noth se navorsingsresultate en die gewysigde hipoteses hoef ewe min beredeneer te word in 'n artikel van hierdie aard (vgl o a Würtwein 1994:111; Nelson 1981:13-28; Peckham 1985:73; O'Brien 1989:3-22,288-292; Cortese 1990: 179-190). Dieselfde geld die vrae oor en moontlike oplossings vir die klaarblyklike inherente spanning in die Deuteronomistiese geskiedenis ${ }^{1}$.

Die vertrekpunt by die skryf van hierdie artikel is dat elke teologiese geskrif in ' $\mathrm{n}$ mindere of meerdere mate ' $n$ polemiese of apologetiese inslag het. Die vraag wat dit is waarteen gepolemiseer of verdedig word, is van beslissende belang vir ' $n$ historiese verstaan van 'n korpus soos die Deuteronomistiese geskiedenis. 'n Hipotese oor die polemiese gerigtheid bring noodwendig mee dat keuses gemaak moet word met betrekking tot

* die ontstaanstyd van die betrokke materiaal; en

* die redaksionele gelaagdheid in die boek of korpus. 
Daar is onder akademici nie eenstemmigheid oor die datering van die verskillende stadia in die ontstaansgeskiedenis van die Deuteronomistiese geskiedenis nie. Dit wissel volgens elke navorser se definisie van wat Deuteronomisties, Deuteronomistiese redaktor, ensovoorts beteken, sowel as elke navorser se identifisering van verskillende redaksionele bewerkings ${ }^{2}$. Sonder om die gronde vir die keuse aan te dui, word die Babiloniese ballingskap gekies as verstaansraamwerk vir die Deuteronomistiese geskiedenis. Dit stem ooreen met die standpunt van die oorwig van navorsers en kan op literêre, religieuse en ander gronde beredeneer word ${ }^{3}$. Daarmee word nie ontken dat daar ná die tyd van die ballingskap nog redaksionele toevoegings gemaak is nie. Die Babiloniese ballingskap en die omstandighede wat dit meegebring het, het die finale vorm van die Deuteronomistiese geskiedenis egter beslissend bepaal. Redaksionele toevoegings ná die ballingskap het nie die seggingskrag van dié magistrale werk wesenlik verander nie.

\section{ENKELE OPMERKINGS OOR DIE AGTERGROND WAARTEEN DIE DEUTERONOMISTIESE GESKIEDENIS VERSTAAN MOET WORD}

Die Nieu-Babiloniese ryk het vanaf die einde van die sewende tot die middel van die sesde eeu 'n dramatiese omwenteling gebring in die bestaan van die geloofsgemeenskap in Juda en Jerusalem. Die staat Jerusalem-Juda is nie net vernietig nie; die geloofsgemeenskap is vir alle praktiese redes gedegradeer tot 'n non-entiteit in die volkesee. Die feit dat die kultus getermineer is en dat die simbole van JHWH se teenwoordigheid ò vernietig of weggevoer is om toegevoeg te word tot die tempelskat van die Babiloniese gode, was 'n onbeskryflike traumatiese ervaring vir die gelowige Judeërs. Dit het hulle vir alle praktiese redes sonder ' $n$ god gelaat. En as hulle hulle JHWH tog kon indink sonder 'n tempel, was Hy in elk geval 'n magtelose god teenoor die gode van die Babiloniërs.

Die ontnugtering het ernstige teologisering noodsaaklik gemaak. Vrae oor God, oor sy almag, sy soewereiniteit, sy verhouding met die uitverkore volk, oor Israel-Juda se verlede, maar veral oor die toekoms, was aan die orde van die dag. Hierdie teologiese nadenke het neerslag gevind in literatuur waarvan die Deuteronomistiese geskiedenis ' $n$ baie belangrike deel is. Die trauma van die ballingskap en die teologisering wat dit meegebring het, het die geloofsgemeenskap wesenlik verander. Israel-Juda as volk van God en as staat, het oorgegaan in Israel as volk van God en 'kirchliche Versammlung' (Hossfeld 1987:123).

\section{DIE VERBOND AS TEOLOGIESE ORIËNTASIEPUNT}

In die Deuteronomistiese geskiedenis word die verhouding tussen JHWH en sy volk primêr as 'n verbondsverhouding gesien. Die boek Deuteronomium is nie net gestruktureer as 'n verbondsdokument nie (McCarthy 1978), maar die verbond vorm skering 
en inslag van die teologiese inhoud van die boek. Op sy beurt dien hierdie teologiese inhoud weer as primêre oriëntasiepunt in die res van die Deuteronomistiese geskiedenis. Veral die saak van lojaliteit teenoor JHWH en die radikale afwysing van afgodediens is een van die sterkste ankerpunte in dié gedeeltes waar die optrede van lede van die geloofsgemeenskap geëvalueer word (vgl bv Jos 1:7; 24:10-17; Rig 1:1114; 3:5-8; 10:6-7; 1 Sam 12:7-11; 2 Sam 12:9; 1 Kon 11:4-13; 15:11-13; 16:30-33).

Die verbond het as teologiese verstaansraamwerk waarskynlik oor eeue ontwikkel in die geloofsgemeenskap wat as 'Israel' aangedui word. Die inhoud wat 'verbond' in die boek Deuteronomium kry en die beklemtonings wat spesifieke aspekte vani die verbond in die Deuteronomistiese geskiedenis ontvang, het die verbond as verstaansraamwerk uitmuntend geskik gemaak vir teologiese nadenke oor God-in-verhouding-met-Israel in die tyd van die ballingskap.

Dit het nie net die moontlikheid gebied om die hele vraag oor die besit en verlies van die land in te trek in die verhouding JHWH-Israel nie. Dit het as sodanig ook die soewereiniteit en alleenheerskappy van JHWH as voorwaarde en vertrekpunt vir sy verhouding met mense in 'n panteïstiese omgewing beklemtoon. Dit het verder die moontlikheid gebied om teologoumena wat met mekaar in spanning verkeer, gelyktydig te handhaaf, soos die absolute eis om lojaliteit aan die mens as voorwaarde vir die voortsetting van die verbondsverhouding, èn die realiteit dat God allén verantwoordelik is vir die bestaan en voortbestaan van die verbondsverhouding.

\section{BELANGRIKE TENDENSE IN DIE TEOLOGIESE INHOUD VAN DIE DEUTERONOMISTIESE GESKIEDENIS ${ }^{4}$}

Die volle teologiese inhoud van die Deuteronomistiese geskiedenis kan uit die aard van die saak nie hier aan die bod kom nie. Die probleem van die inherente spanning in die Deuteronomistiese geskiedenis wat waarskynlik teruggevoer kan word na 'n meer optimistiese redaksionele fase in die tyd van koning Josia en 'n meer pessimistiese redaksionele fase in die tyd van die ballingskap, met ander woorde die vraag oor die teologieë van die Deuteronomistiese geskiedenis, word ook nie hier bespreek nie. Wat wel hier aangebied word, word na vore gebring en geprofileer deur

* die vraagstelling na die wesenlike identitieit en konstituerende elemente van die geloofsgemeenskap wat in die Deuteronomistiese geskiedenis na vore kom; en

* die keuse van die Babiloniese ballingskap as gerekonstrueerde agtergrond vir die verstaan van die Deuteronomistiese geskiedenis. 


\subsection{JHWH die God van die verbond}

Die Deuteronomistiese geskiedenis praat oor JHWH nooit anders as God-in-verhouding-met-mense nie. Die beeld wat van JHWH na vore kom in sy verhouding met mense, soos wat dit gekommunikeer word deur die hervertelling van die 'geskiedenis' van Israel-Juda, is dié van 'n unieke God wat absoluut soewerein heers oor lewe en dood en wie se almag die grootste eerbied en respek afdwing.

Dat JHWH 'n unieke God is, word in soveel woorde in Deuteronomium 6:4 gesê - 'n gedeelte wat vanaf die vroegste tye verstaan is as 'n samevatting van die wesenlike inhoud van Deuteronomium; trouens van die hele Torah (vgl Mark 12:29). Daar kan naamlik goeie argumente aangevoer word om Deuteronomium 6:4 te vertaal:

Hoor Israel

JHWH is ons God

JHWH is enig/uniek.

Die uniekheid van JHWH is (binne die verband van die Deuteronomistiese geskiedenis) daarin geleë dat Hy Israel met 'n magsvertoon uit Egipte bevry en hulle gelei het, dat Hy Hom direk met Israel bemoei het deur met hulle te praat en met hulle 'n verbond te sluit (Deut 4:7-12, 32-39). Sy uniekheid is ook daarin geleë dat Hy op geen wyse afgebeeld kan word nie (Deut 4:12-23), dat Hy oordeel en straf (Deut 4:24-28), maar tog ook genadig is (Deut 4:30-31). Hy is nooit só gebonde aan simbole dat mense oor Hom beheer kan kry nie (1 Sam 4:1-11; 1 Kon 8:27), maar die tekens van sy teenwoordigheid moet tog met die hoogste moontlike agting bejeën word ( 1 Sam 5:1-6:20; 2 Sam 6:1-15).

In die Deuteronomistiese geskiedenis word ook groot klem gelê op die absolute soewereiniteit van JHWH. Dit is die vooronderstelling van die verbond dat 'n magtige soewereine heer met magteloses in verhouding tree. JHWH se verkiesing van Israel bevestig sy soewereiniteit. Daar was by Israel niks aanwesig op grond waarvan Hy met hulle in 'n verhouding moes tree, behalwe die belofte wat Hy self gemaak het nie (Deut $7: 6-8 ; 9: 3-6 ; 32: 8-14)$. Dat JHWH soewerein Heer is oor alles, word bevestig deur die feit dat Hy ook 'n belofte wat Hy self gemaak het, kan verander (1 Sam 2:27-30). Hy word in liedere besing as dié Een wat vrymagtig beskik oor lewe en dood sonder dat iemand Hom tot verantwoording kan roep (Deut 32:39; 1 Sam 2:2-10, 25). Sy soewereiniteit blyk ook uit die veronderstelling waarvan Dawid uitgaan dat JHWH 'n oordeelswoord wat Hy uitgespreek het, kan terugtrek (2 Sam 12:14-23). Die absolute soewereiniteit van JHWH kom ook daarin na vore dat Hy Saul finaal verwerp omdat hy ongehoorsaam was, terwyl Dawid wat gruweliker dinge gedoen het, nie verwerp word nie. Die aangrypende sondebelydenis van Saul word nie aanvaar nie, terwyl dié van Dawid wel aanvaar word (vgl 1 Sam 15:24-26 met 2 Sam 12:13v). 
Die Deuteronomistiese geskiedenis is ' $\mathrm{n}$ indrukwekkende getuienis van die almag van JHWH. Dit word uitdruklik gesê (Deut 10:14, 17; 2 Sam 7:22), maar word ook bevestig deur sy magtige dade in die geskiedenis (Jos 3; 6; Rig 7). JHWH se almag word ook onderbou deur die oorwinning van die Assiriërs en Babiloniërs en die vernietiging van die state Israel en Juda, as die oordele van JHWH oor die ontrou van sy volk, voor te hou (2 Kon 17:1-20;18:11; 21:7-15;23:26). Sy almag word veral betuig wanneer Hy teenoor ander sogenaamde gode te staan kom (1 Kon 18). Daar is trouens geen ander mag waarmee 'n mens rekening hoef te hou nie. Ook dit wat aan die bose toegeskryf sou kon word, staan onder beheer van JHWH (1 Sam 16:14-16, 23). JHWH kan ook besluit om Dawid aan te hits om iets te doen waarvoor Hy hom en die volk later straf (2 Sam 24:1-17). Daar is dus géén ander mag naas JHWH nie. JHWH se almag blyk ook daaruit dat Hy die geskiedenis beheer. Hy maak sy besluite oor persone bekend deur sy profete, en elke keer verloop die gebeure presies soos Hy vooraf besluit het (1 Sam 28:1-19; 1 Kon 11:26-40; 13:1; 14:1-16; 21:1-22:38).

Deur die beklemtoning van JHWH se uniekheid, soewereiniteit en almag, het die Deuteronomistiese geskiedenis in die tyd van die Babiloniese ballingskap antwoord gegee op die vraag na die oënskynlike magteloosheid van JHWH teenoor die gode van die ander nasies, veral dié van die Babiloniërs.

\subsection{Israel die volk van die verbond}

Israel leef as verbondsvolk in die teenwoordigheid van die lewende God. JHWH se uniekheid, sy soewereiniteit en sy almag hou in dat die volk absolute respek en eerbied vir Hom sal hê en dat hulle lojaliteit aan Hom sal bewys deur gehoorsaamheid.

Dat JHWH se almag eerbied eis, is vanselfsprekend (1 Sam 2:2). Wie nie 'n gesindheid van eerbied openbaar nie, word deur Hom geoordeel (1 Sam 2:10, 27-30). Die eerbied vir JHWH hou natuurlik ook met sy soewereiniteit verband. $H y$ besluit of Hy aan 'n mens genade bewys en of Hy oordeel. Hy besluit of Hy die verbond hou of dit tot niet maak. Verootmoediging voor JHWH en eerbied vir die beskikker oor lewe en dood, maak die moontlikheid vir genade en ontferming van sy kant af oop (1 Kon 8:28-53), maar uiteindelik besluit Hy alleen. Dit pas 'n magtelose soos Israel, wat uit genade ingetrek is in die verbond met JHWH, om vir Hóm alleen die grootste respek te hê.

Hierdie eerbied vir JHWH kom onder andere tot uitdrukking in 'n allesomvattende lojaliteit en diens aan Hom. In die boek Deuteronomium word hierdie lojaliteit aangedui met die begrip 'liefde'. Dié lojaliteit (liefde) word bewys deur gehoorsaamheid aan die bepalings van die verbond (vgl Deut 10:12 waar eerbied, liefde en gehoorsaam- 
heid as reaksie op JHWH se vergifnis geeis word). Daar is ook geen deel van 'n gelowige se lewe wat uitgesluit is uit hierdie eis om lojaliteit en gehoorsaamheid nie. Teenoor die God van die verbond bestaan daar nie iets soos privaatheid nie (Deut 6:49). Sy redding en die genade wat Hy bewys het, gee Hom aanspraak op die totale lewe van die mens (Deut 5:6-21). Lewensomvattende eerbied, lojaliteit en gehoorsaamheid teenoor JHWH die almagtige, soewereine God, is die antwoord op sy genadige toewending tot die mens.

Vir die volk in ballingskap was daar hoop in die profetewoord. Die profetewoord wat vervul word, was nie net 'n teken dat God in sy almag die geskiedenis stuur en rig nie. Die profetewoord wat vervul word, het die moontlikheid ingehou dat JHWH ook ánder profetewoorde en beloftes waar sal maak (Deut 30; 31:14-21; 32:35-43; 2 Sam 7:12-16, 25-29). Die betroubare, skeppende profetewoord wat JHWH se oordele aankondig en dit 'n werklikheid maak, skep ook die hoop op 'n nuwe toekoms.

\subsection{Die verbond tussen JHWH en Israel}

Die verbond druk die verhouding tussen JHWH en Israel uit. Hierdie verbond of verhouding word deur JHWH tot stand gebring en in stand gehou (Deut 7:6-9). Daar bestaan hoegenaamd geen rede waarom JHWH dit sou doen, anders as uit genade nie. Israel se status as klein slawevolkie, maar veral ook Israel se geskiedenis van ontrou en ongehoorsaamheid, het hulle seker die slegste keuse gemaak (Deut 9:5-24). Dat JHWH hulle wel gekies het en nieteenstaande hulle ontrou die verbond in stand gehou het, kan alleen toegeskryf word aan sy onlogiese genade en liefde. Dié soort liefde en trou is alleen by die lewende God te vinde (Deut 7:7-9). Dieselfde liefde duld egter geen kompetisie van 'n derde party nie. Daarom bring die verbond met JHWH 'n dialektiese spanning: die verbond kom tot stand deur JHWH se liefde en genade en word in stand gehou omdat dieselfde liefde en genade ook vergifnis moontlik maak, en tòg staan elkeen wat ontrou is en die verbond verbreek onder die oordeel (Deut 7:9v). So word die verbond juis vanweë die genade én die oordeel wat dit inhou, 'n durende appèl tot toewyding aan die God van die verbond (Deut 7:11-26, vgl ook die byna skematiese refrein van sonde-oordeel-berou-genade in die boek Rigters).

In die Deuteronomistiese geskiedenis word daarop klem gelê dat die verbond nie iets onpersoonliks is waarby ánder mense betrokke is en waaroor die lede van die geloofsgemeenskap kan spekuleer nie. Elke lid van die geloofsgemeenskap is persoonlik ingetrek in hierdie verhouding met JHWH en het eintlik self by Sinai-Horeb voor Hom gestaan (Deut 5:1-4; vgl die gebruik van 'ons' in Deut 6:20-25; vgl ook Deut 30:11-15). 
Die Deuteronomistiese geskiedenis lê ook swaar klem daarop dat daar net één God, één verbond met Israel en daarom net één verbondsvolk is. Dit word onder andere begrond met die bevel om die kultus net op een plek te beoefen, naamlik die plek wat JHWH sal uitkies en waar sy Naam sal woon ${ }^{5}$. Vanuit hierdie vertrekpunt word alle ander kultusplekke naas Jerusalem veroordeel as sonde (1 Kon 12:26-33) en word elke Israelitiese koning beoordeel aan die hand van die vraag of hy voortgegaan het met die instandhouding van ander kultusplekke naas Jerusalem (2 Kon 10:29; 13:2; 14:24, ens). Daarom word Josia se pogings om die kultus te sentraliseer in Jerusalem so hoog aangeprys (2 Kon 23:1-25). Die eenheid van die verbond, dit wil sê die eenheid van die geloofsgemeenskap word gehandhaaf oor die politieke en staatkundige grense van Israel en Juda heen (vgl 1 Kon 12:21-24).

Binne hierdie één verbondsvolk dra almal, gesamentlik en afsonderlik verantwoordelikheid vir mekaar. Hierdie verantwoordelikheid word begrond met die barmhartigheid en toegeneëntheid wat elke Israeliet van JHWH ontvang het, en kom in die besonder tot uitdrukking in die barmhartige optrede teenoor medegelowiges, veral hulle wat weerloos is in die samelewing (Deut 14:28-15:18).

\section{ENKELE GEDAGTES MET DIE OOG OP NADENKE OOR DIE KERK- BEGRIP}

Die Deuteronomistiese geskiedenis laat geen twyfel daaroor dat 'n geloofsgemeenskap alleen kan bestaan in verbondenheid met die een, lewende God nie. Dit is nie net die grond van sy bestaan nie, maar is ook die sin van die lewe.

Die lewende God skep hierdie verhouding met mense en hou dit in stand. So is hulle bestaan as geloofsgemeenskap volledig afhanklik van Hom. Dat Hy bereid is om in verhouding te tree met mense wie se status en verlede hulle by voorbaat volkome ongeskik maak vir so 'n verhouding, getuig van sy onlogiese liefde en onbeskryflike genade.

Die almag en soewereiniteit van God bring ' $n$ bepaalde spanning in sy verhouding met mense: Hy kán besluit om nie die pád met hulle verder te loop nie. Die spanning word verder verhoog deur die realiteit van sy oordeel oor ontrou en ongehoorsaamheid. Dit beteken dat die geloofsgemeenskap se hoop alleen gevestig kan wees in die genade en liefde van God. Hulle is resloos uitgelewer aan God se beslissings oor hulle lewens. Die enigste vastigheid wat hulle het, is die genade, liefde, vergifnis en trou van hierdie God aan Wie hulle uitgelewer is.

Hierdie vastigheid word geskep en versterk deur die profetewoord wat verlede en toekoms byeenbring. Daar is geen sigbare simbole wat aan die geloofsgemeenskap 'n houvas gee op die God met Wie hulle in verhouding staan nie. Die onbewysbare profe- 
tewoord skep hoop vir die toekoms, juis deur die geloofsgemeenskap te verseker dat hulle uitgelewer is aan die almagtige God wat met toegeneëntheid absoluut soewerein heers oor hulle lewens.

Die almag, soewereiniteit, liefde en genade van God word 'n durende appèl tot 'n lewe van volkome toewyding aan Hom, 'n lewe wat gekenmerk word deur heilige eerbied en ' $n$ lewenslojaliteit wat die totale lewe omvat en wat teen alle ervaring in gehandhaaf word. Hierdie lewe van toewyding geld die geloofsgemeenskap as geheel, maar ook elke afsonderlike lid daarvan, omdat elkeen self 'teenwoordig' was by God se reddingsdaad in die verlede.

Die verbondenheid met God bind ook die lede van die geloofsgemeenskap aan mekaar. Die eerbied vir God en die lojaliteit teenoor Hom kry gestalte in die houding en optrede teenoor medegelowiges, veral diegene wat weerloos is. 'n Persoon of gemeenskap wie se bestaan gegrond is in die genade, liefde en vergifnis van God, kan nie die grond van sy bestaan loën in sy houding en optrede teenoor ander nie.

Omdat daar één God is, is daar wesenlik én geloofsgemeenskap. Hierdie wesenlike eenheid moet oor alle grense van politieke en staatkundige verdeeldheid heen, gehandhaaf word. Die vraag hó dit gedoen moet word, sal in die lig van gegewens uit die Nuwe Testament beantwoord moet word (vgl bv die kritiek van Joh 4:21-23 op die 'hoe' van die Deuteronomistiese geskiedenis).

\section{ENDNOTAS}

1 Vergelyk byvoorbeeld die standpunte van Wolff (1961:174) en daarteenoor Von Rad (1962:343), Brueggemann (1968:400) en Gray (1970:773-775) oor die vraag of daar in 2 Konings 'n negatiewe of positiewe messiaanse verwagting is.

2 Vergelyk byvoorbeeld die aanduidings $\operatorname{Dtr}^{1}, \operatorname{Dtr}^{2}, \mathrm{DtrN}, \mathrm{DtrG}, \mathrm{DtrS}, \mathrm{Dtr} \mathrm{P}$, ensovoorts by verskillende navorsers.

3 Vergelyk byvoorbeeld die omvattende werk van Weinfeld (1972).

4 Die inhoud wat hier aangebied word, is 'n eie lees en verstaan van die boeke wat saam die Deuteronomistiese geskiedenis vorm. Die wortels van hierdie eie lees en verstaan lê versprei in kommentare, maar lê veral ook versprei in eie ongepubliseerde eksegetiese studies. Die verwysing na gedeeltes in die Deuteronomistiese geskiedenis is nie bedoel om volledig te wees nie, maar dien meestal as geselekteerde voorbeelde.

5 Vergelyk Von Rad (1953:37-44) vir die gebruik van die 'Naam' van JHWH in Deuteronomium. 


\section{Literatuurverwysings}

Brueggemann, W 1968. The kerygma of the Deuteronomistic historian. Interp. 22, 387-402.

Cortese, E 1990. Theories concerning Dtr: A possible rapprochement, in Brekelmans, C \& Lust, J (eds), Pentateuchal and Deuteronomistic studies, 179-190. Papers read at the XIIIth IOSOT meeting, Louvain 1989. Leuven: University Press.

Gray, J 1970. I \& II Kings. Philadelphia: Westminster.

Hossfeld, E-L 1987. Volk Gottes als 'Versammlung', in Schreiner, J (Hrsg), Unterwegs zur Kirche: Alttestamentliche Konzeptionen, 123-142. Freiburg: Herder.

McCarthy, D J 1978. Treaty and covenant. Rome: Biblical Institute.

Nelson, R D 1981. The double redaction of the Deuteronomistic history. Sheffield: JSOT.

Noth, M 1943. Uberlieferungsgeschichtliche Studien. Halle: Max Niemeyer.

O'Brien, M A 1989. The Deuteronomistic history hypothesis: A reassessment. Göttingen: Vandenhoeck.

Peckham, B 1985. The composition of the Deuteronomistic history. Atlanta: Scholars Press.

Stendebach, F-J 1984. Versammlung - Gemeinde - Volk Gottes: Alttestamentliche Vorstufen von Kirche? Judaica 40, 211-224.

Von Rad, G 1953. Studies in Deuteronomy. London: SCM.

- 1962. Old Testament theology. New York: Harper \& Row.

Weinfeld, M 1972. Deuteronomy and the deuteronomic school. Oxford: Clarendon.

Wolff, H W 1961. Das kerygma des deuteronomistischen Geschichtswerkes. ZAW 73, 171-185.

Würtwein, E 1994. Studien zum Deuteronomistischen Geschichtswerk. Berlin: De Gruyter. 